\title{
Expanding the pool of cardiac donors: Is it really possible after cardiac arrest?
}

\author{
Louis P. Perrault, MD, PhD, and Michel Carrier, MD, MBA
}

\author{
From the Department of Surgery, Montreal Heart Institute, Université de Montréal, Montreal, Quebec, Canada. \\ Disclosures: Authors have nothing to disclose with regard to commercial support. \\ Received for publication Nov 3, 2016; accepted for publication Nov 4, 2016; available ahead of print Dec 9, 2016. \\ Address for reprints: Michel Carrier, MD, MBA, Montreal Heart Institute, Université de Montréal, 5000 Belanger \\ St, Montreal, Quebec H1T 1C8, Canada (E-mail: michel.carrier@icm-mhi.org). \\ J Thorac Cardiovasc Surg 2017; 153:631 \\ $0022-5223 / \$ 36.00$ \\ Copyright (c) 2016 by The American Association for Thoracic Surgery \\ http://dx.doi.org/10.1016/j.jtcvs.2016.11.016
}

The article in this issue of the Journal, Galeone and colleagues ${ }^{1}$ from Paris reports the results of heart transplants with 117 donors who had sustained resuscitated cardiac arrest. These donors had high-risk characteristics for successful transplantation, such as anoxic cause of death and elevated peak troponin $\mathrm{T}$ levels, although they were younger (44 years) at procurement than were the usual nonarrested donors and had a normal left ventricular ejection fraction. Immediate results after transplant, 30-day mortality, and the incidence of primary graft failure were similar between recipients of donors who had sustained resuscitated cardiac arrest and those who had not. A possible conclusion from this experience could be to expand criteria for donor selection and increase the pool of cardiac donors.

Before doing so, we should first look more closely at the clinical results. Extracorporeal membrane oxygenation for primary graft dysfunction was used in $30 \%$ of overall recipients in both groups, dialysis for acute renal failure was used in $29 \%$, and the 30-day overall mortality after transplant was $16 \%$. These results could be acceptable only for high-risk recipients. Moreover, Galeone and colleagues ${ }^{1}$ reported better 5- and 10-year survivals for transplant recipients with a resuscitated arrested donor heart. This finding is difficult to explain other than that resuscitated arrested heart donors were younger at procurement than were other donors and had a preserved left ventricular ejection fraction.

If a short period of cardiac arrest does not negatively affect recipients' outcomes, at least for high-risk candidates, the next step to expand the pool of organ donors could be to perform heart transplants from non-heart beating donors or from donors who died of cardiocirculatory causes (donation after cardiac death) as opposed to only those with the usual declaration of brain death. Although the use of hearts from donors who died of cardiocirculatory causes has already been reported, ${ }^{2}$ the practice has not countries. $^{3}$ many countries.

\section{References}

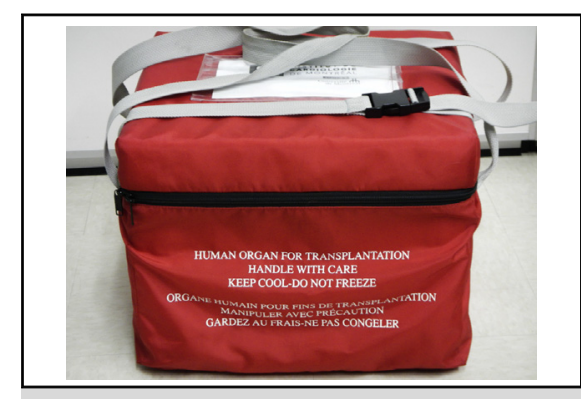

Cold preservation and transportation of a human donor heart.

\section{Central Message}

The pool of cardiac donors can be expanded by using resuscitated arrested hearts.

See Article page 622.

been generalized, nor is it commonly performed in most

Galeone and colleagues ${ }^{1}$ have clearly shown that young donors with a history of resuscitated cardiac arrest of short duration, from anoxia at the initial event, and with normal left ventricular ejection fraction at the time of procurement could be used with caution for high-risk recipients. In the current era of donor organ shortage, especially for heart transplants, the transplant community will have to reflect on expanding the donor pool in reassessing the potential use of hearts from patients donating through the donation after cardiac death process. Technical, ethical, and legal aspects will need to be resolved. This may take years, but the legislation regarding the rights related to end of life care and to organ donation is rapidly evolving in

1. Galeone A, Varnous S, Lebreton G, Barreda E, Hariri S, Pavie A, et al. Impact of cardiac arrest resuscitated donors on heart transplant recipients' outcome. J Thorac Cardiovasc Surg. 2017;153:622-30.

2. Boucek MM, Mashburn C, Dunn SM, Frizell R, Edwards L, Pietra B, et al. Denver Children's Pediatric Heart Transplant Team. Pediatric heart transplantation after declaration of cardiocirculatory death. $N$ Engl J Med. 2008;359:709-14.

3. Veatch RM. Donating hearts after cardiac death-reversing the irreversible. $N$ Engl J Med. 2008;359:672-3. 